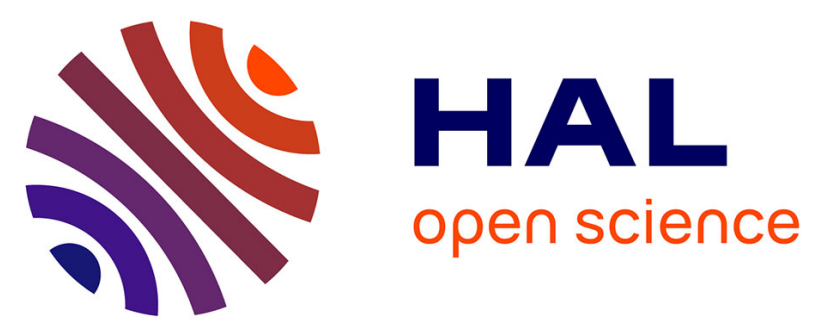

\title{
Letter: Postoperative Hearing Preservation in Patients Undergoing Retrosigmoid Craniotomy for Resection of Vestibular Schwannomas: A Systematic Review of 2034 Patients
}

Constantin Tuleasca, Roy Thomas Daniel, Daniele Starnoni, Mercy George, Raphael Maire, Marc Levivier

\section{To cite this version:}

Constantin Tuleasca, Roy Thomas Daniel, Daniele Starnoni, Mercy George, Raphael Maire, et al.. Letter: Postoperative Hearing Preservation in Patients Undergoing Retrosigmoid Craniotomy for Resection of Vestibular Schwannomas: A Systematic Review of 2034 Patients. Neurosurgery, inPress, 10.1093/neuros/nyz367 . hal-02290045

\section{HAL Id: hal-02290045 \\ https://hal.sorbonne-universite.fr/hal-02290045}

Submitted on 17 Sep 2019

HAL is a multi-disciplinary open access archive for the deposit and dissemination of scientific research documents, whether they are published or not. The documents may come from teaching and research institutions in France or abroad, or from public or private research centers.
L'archive ouverte pluridisciplinaire HAL, est destinée au dépôt et à la diffusion de documents scientifiques de niveau recherche, publiés ou non, émanant des établissements d'enseignement et de recherche français ou étrangers, des laboratoires publics ou privés. 


\title{
Letter: Postoperative Hearing Preservation in Patients Undergoing Retrosigmoid Craniotomy for Resection of Vestibular Schwannomas: A Systematic Review of 2034 Patients
}

\author{
Constantin Tuleasca ${ }^{1,2,3,4,5,6}$, MD-PhD, Roy Thomas Daniel ${ }^{1,2}$, MBBS, MCh, Daniele \\ Starnoni $^{1}$, MD, Mercy George ${ }^{7}, \mathrm{MD}$, Raphael Maire ${ }^{7}, \mathrm{MD}$, Marc Levivier ${ }^{1,2}, \mathrm{MD}, \mathrm{PhD}$ \\ ${ }^{1}$ Department of Clinical Neurosciences, Neurosurgery Service and Gamma Knife Center, Lausanne \\ University Hospital (CHUV), ${ }^{2}$ University of Lausanne (Unil), Faculty of Biology and Medicine \\ (FBM), ${ }^{3}$ Signal Processing Laboratory (LTS 5), Ecole Polytechnique Fédérale de Lausanne (EPFL), \\ ${ }^{4}$ Sorbonne Université, Faculté de Médecine, ${ }^{5}$ Assistance Publique-Hôpitaux de Paris, Hôpitaux \\ Universitaires Paris-Sud, Centre Hospitalier Universitaire Bicêtre, Service de Neurochirurgie, Paris, \\ France; ${ }^{6}$ Sorbonne Université, Faculté de Médecine; ${ }^{7}$ ENT Department, Lausanne University Hospital
}

Corresponding author: Constantin Tuleasca, MD-PhD, Assistance Publique-Hôpitaux de Paris, Hôpitaux Universitaires Paris-Sud, Centre Hospitalier Universitaire Bicêtre, Service de Neurochirurgie, Paris, France; Sorbonne Université, Faculté de Médecine; Centre Hospitalier Universitaire Vaudois, Neurosurgery Service and Gamma Knife Center, Rue du Bugnon 4446, BH-08, CH-1011, Lausanne, Switzerland;

Tel: +41-21-314-26-02; Fax: +41-21-314-11-99; e-mail: constantin.tuleasca@gmail.com

\section{Funding:}

Constantin Tuleasca gratefully acknowledges receipt of a 'Young Researcher in Clinical Research Grant' (Jeune Chercheur en Recherche Clinique) from the University of Lausanne (UNIL), Faculty of Biology and Medicine (FBM) and the Lausanne University Hospital (CHUV).

\section{Conflict of interest:}

None. 
Dear Editor,

We have read with great interest the recent article published in Neurosurgery, related to postoperative hearing preservation in patients undergoing retrosigmoid craniotomy for resection of vestibular schwannomas (VSs) ${ }^{1}$. Tumor size data were stratified to compare hearing after surgery for intracanalicular, small $(0-20 \mathrm{~mm})$ and large $(>20 \mathrm{~mm})$ tumors. Aggregate hearing preservation was $31 \%$ and $35 \%$ under a fixed and random effect, respectively. Depending on the tumor size the rate was $57 \%, 37 \%$ and $12 \%$, respectively, for intracanalicular, small and large tumors. There was a high heterogeneity, with hearing preservation rates ranging form $0-100 \%$.

Vestibular schwannoma management has been of constant neurosurgical debate during the past 20 years $^{2}$. Current treatment possibilities include observation, stereotactic radiosurgery (SRS) and microsurgery (MS) ${ }^{3}$. For intracanalicular tumors, the "wait-and-scan" approach has been further challenged by the proactive SRS treatment ${ }^{4}$, as the former had been suggested to better preserve hearing on long-term basis, especially in patients with high-level of hearing pretherapeutically, absence of subjective hearing loss in patients with GarnerRobertson $1^{5}$ or younger age ${ }^{6}$. In general, small to medium size tumors can be offered SRS. The recent International Stereotactic Radiosurgery Society (ISRS) guidelines have stated that for marginal doses between 12-14 Gy, in single fraction, SRS and particularly Gamma Knife allows facial nerve House-Brackmann grade I in 95-100\% and hearing preservation rates between $41-79 \%$ at 5 years $^{7}$. Large VS with symptomatic mass effect are common MS indication ${ }^{8}$. Samii et al. ${ }^{9}$ reported hearing preservation of $11 \%$ after total excision of large VS. In the present systematic review, hearing preservation rates for large tumors was $12 \%$.

An open question is whether new type of approaches, in particular subtotal resection followed by SRS ${ }^{10}$ could be of help in improving hearing outcome in large VS. However, the definition of subtotal, gross total or near-gross total resection suffers from a heterogeneity definition in the current literature. A recent systematic review ${ }^{11}$ suggested functional nerve preservation of $91.6 \%$ (95\% CI 93.7\%-98.5\%) and serviceable hearing preserved in $59.9 \%$ (95\% CI 36.5\%-83.2\%) after planned subtotal resection followed by SRS. Moreover, it is now well acknowledged that the risk of cancerogenesis after SRS remains extremely rare ${ }^{12}$ and similar to the risk of development of such tumor even in the absence of prior radiation. However, there is currently no consensus whether SRS should be applied at a latter time in case of remnant tumor growth ${ }^{13}$ or shortly after MS, without further «wait-and-scan » 
strategy ${ }^{14}$, shall a subtotal resection be applied. «Optimal resection ${ }^{13}$ has been suggested, which can be perceived differently from one center to another ${ }^{15}$. How optimal is optimal remains so a matter of additional debate.

A supplementary aspect is whether large tumors should be considered those greater than $20 \mathrm{~mm}$, or greater than $30 \mathrm{~mm}$ etc. The results might vary also in terms of outcome, although globally larger tumors are known to be associated with poorer outcomes. In a series of 54 patients with preserved hearing at the time of surgery and VS $\geq 20 \mathrm{~mm}$ of extrameatal diameter, hearing preservation was achieved in $53.7 \%$, but only $31 \%$ had maintenance (or improvement) of hearing at the same level as before surgery ${ }^{16}$. Furthermore, Ansari et al. ${ }^{17}$ reported on 127 patients with $\mathrm{VS} \geq 30 \mathrm{~mm}$ with postoperative hearing preservation in only $28.3 \%^{17}$, while Di Maio et al. only $21.4 \%^{18}$. In series performing combined approaches, hearing preservation rates after MS and GK have been reported to be as high as $82 \%{ }^{19}$.

Recently, intraoperative adjunctive with cochlear mapping with the mobile cochlear nerve compound action potential tracer in VS surgery has been also suggested ${ }^{20}$. While this device might be useful in cochlear nerve mapping and consequently help in hearing preservation, it has also several limitations. Nevertheless, in this small series, among 8 patients with large tumors (Koos grade III or IV), the rate of successful mapping was $62.5 \%$ (5 patients) and the rate of hearing preservation in patients with large tumors was $50 \%$ (4 patients).

Current strategies for VS have significantly evolved during the past decades. A major challenge is to offer patients with large VS where MS is needed a clinical outcome compared to that of the small to medium size tumors treated usually by SRS. This challenge is reflected in the appearance of new paradigm shifts, such as the subtotal resection followed by SRS. Whether this type of approach would become the "Holy Grail" of this particular skull-base challenging pathology remains to be elucidated by further series, including with long-term follow-up. 


\section{References:}

1. Preet K, Ong V, Sheppard JP, et al. Postoperative Hearing Preservation in Patients Undergoing Retrosigmoid Craniotomy for Resection of Vestibular Schwannomas: A Systematic Review of 2034 Patients. Neurosurgery. 2019.

2. Kondziolka D, Mousavi SH, Kano H, Flickinger JC, Lunsford LD. The newly diagnosed vestibular schwannoma: radiosurgery, resection, or observation? Neurosurgical focus. 2012;33(3):E8.

3. Tuleasca $\mathrm{C}$, Levivier M. A virtual musician quartet with vestibular schwannoma. The Lancet. Oncology. 2018;19(8):1025.

4. Regis J, Carron R, Park MC, et al. Wait-and-see strategy compared with proactive Gamma Knife surgery in patients with intracanalicular vestibular schwannomas: clinical article. Journal of neurosurgery. 2013;119 Suppl:105-111.

5. Mousavi SH, Kano H, Faraji AH, et al. Hearing preservation up to 3 years after gamma knife radiosurgery for Gardner-Robertson class I patients with vestibular Schwannomas. Neurosurgery. 2015;76(5):584-590; discussion 590-581.

6. Kano H, Kondziolka D, Khan A, Flickinger JC, Lunsford LD. Predictors of hearing preservation after stereotactic radiosurgery for acoustic neuroma. Journal of neurosurgery. 2009;111(4):863-873.

7. Tsao MN, Sahgal A, Xu W, et al. Stereotactic radiosurgery for vestibular schwannoma: International Stereotactic Radiosurgery Society (ISRS) Practice Guideline. Journal of radiosurgery and SBRT. 2017;5(1):5-24.

8. Samii M, Matthies C. Management of 1000 vestibular schwannomas (acoustic neuromas): surgical management and results with an emphasis on complications and how to avoid them. Neurosurgery. 1997;40(1):11-21; discussion 21-13.

9. Samii M, Gerganov VM, Samii A. Functional outcome after complete surgical removal of giant vestibular schwannomas. J Neurosurg. 2010;112(4):860-867.

10. Iwai $Y$, Yamanaka K, Ishiguro T. Surgery combined with radiosurgery of large acoustic neuromas. Surgical neurology. 2003;59(4):283-289; discussion 289-291.

11. Starnoni D, Daniel RT, Tuleasca C, George M, Levivier M, Messerer M. Systematic review and meta-analysis of the technique of subtotal resection and stereotactic radiosurgery for large vestibular schwannomas: a "nerve-centered" approach. Neurosurgical focus. 2018;44(3):E4.

12. Wolf A, Naylor K, Tam M, et al. Risk of radiation-associated intracranial malignancy after stereotactic radiosurgery: a retrospective, multicentre, cohort study. The Lancet. Oncology. 2019;20(1):159-164.

13. Troude L, Boucekine M, Montava M, Lavieille JP, Regis JM, Roche PH. Adjunctive Gamma-Knife Surgery Or Wait \& Scan Policy After Optimal Resection Of Large Vestibular Schwannomas: Clinical And Radiological Outcomes. World neurosurgery. 2018.

14. Daniel RT, Tuleasca $\mathrm{C}$, George $\mathrm{M}$, et al. Preserving normal facial nerve function and improving hearing outcome in large vestibular schwannomas with a combined approach: planned subtotal resection followed by gamma knife radiosurgery. Acta neurochirurgica. 2017;159(7):1197-1211.

15. van de Langenberg R, Hanssens PE, van Overbeeke JJ, et al. Management of large vestibular schwannoma. Part I. Planned subtotal resection followed by Gamma Knife surgery: radiological and clinical aspects. Journal of neurosurgery. 2011;115(5):875-884. 
16. Wanibuchi M, Fukushima T, McElveen JT, Jr., Friedman AH. Hearing preservation in surgery for large vestibular schwannomas. J Neurosurg. 2009;111(4):845-854.

17. Ansari SF, Terry C, Cohen-Gadol AA. Surgery for vestibular schwannomas: a systematic review of complications by approach. Neurosurg Focus. 2012;33(3):E14.

18. Di Maio S, Malebranche AD, Westerberg B, Akagami R. Hearing preservation after microsurgical resection of large vestibular schwannomas. Neurosurgery. 2011;68(3):632-640; discussion 640.

19. Tuleasca C, Daniel RT, Starnoni D, George M, Maire R, Levivier M. Letter to the Editor Regarding "Adjunctive Gamma Knife Surgery or Wait and Scan Policy After Optimal Resection of Large Vestibular Schwannomas: Clinical and Radiologic Outcomes". World neurosurgery. 2019;122:719-721.

20. Watanabe $\mathrm{N}$, Ishii $\mathrm{T}$, Fujitsu $\mathrm{K}$, et al. Intraoperative cochlear nerve mapping with the mobile cochlear nerve compound action potential tracer in vestibular schwannoma surgery. Journal of neurosurgery. 2018:1-8. 